\title{
Notes on the vocalizations of Buff-breasted Mountain-tanager (Dubusia taeniata)
}

\section{Peter Boesman}

In the following we briefly analyze and compare voice of the three races of Buff-breasted Mountain-tanager (Dubusia taeniata). We also try to quantify the extent of any vocal differences using the criteria proposed by Tobias et al. (2010), as a support for taxonomic review. We have made use of sound recordings available on-line from Xeno Canto (XC) and Macaulay Library (ML).

An overview of song per race, illustrated with sonograms:

carrikeri ( Santa Marta Mts, in N Colombia)
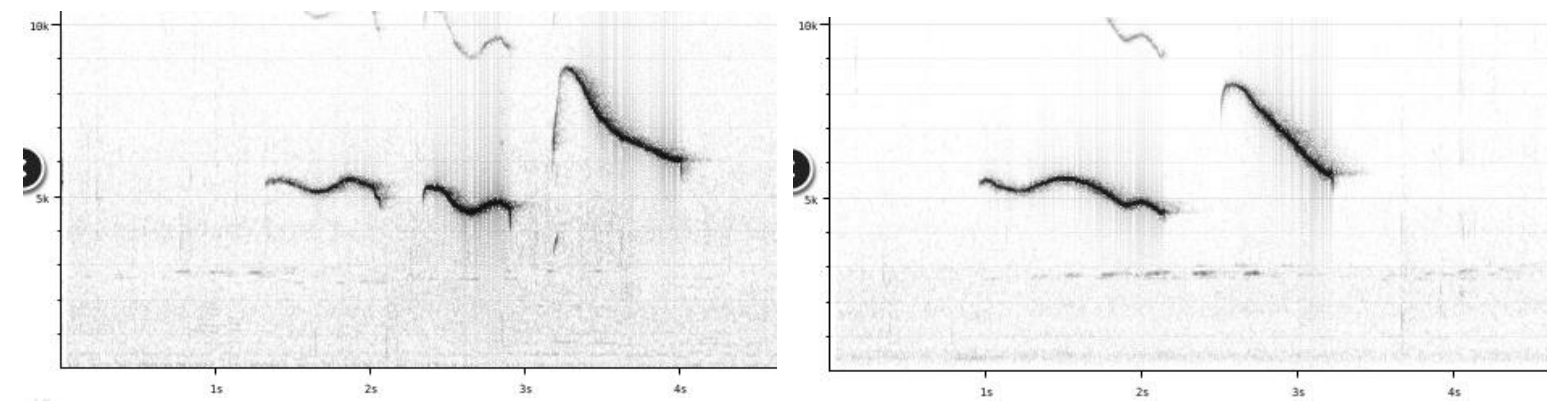

taeniata (Andes of Venezuela S to NW Peru) Venezuela
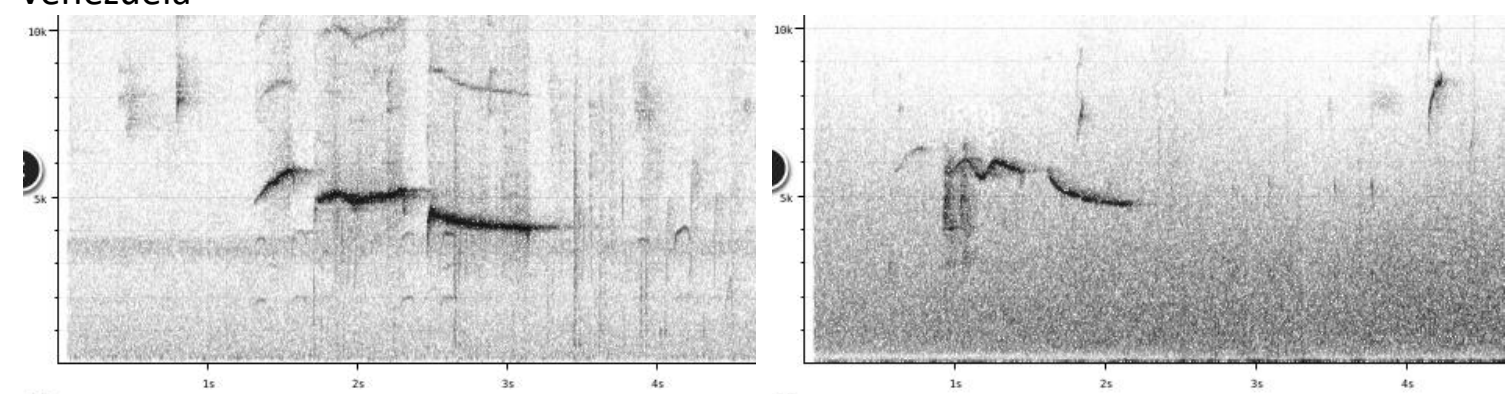

Colombia
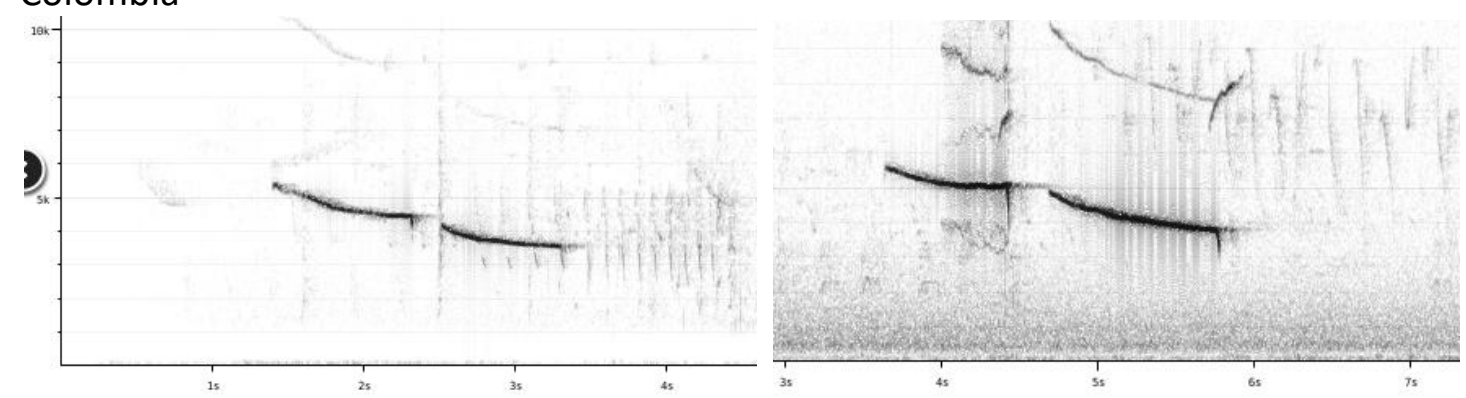


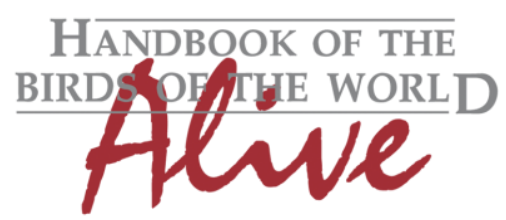

\section{ORNITHOLOGICAL NOTES}
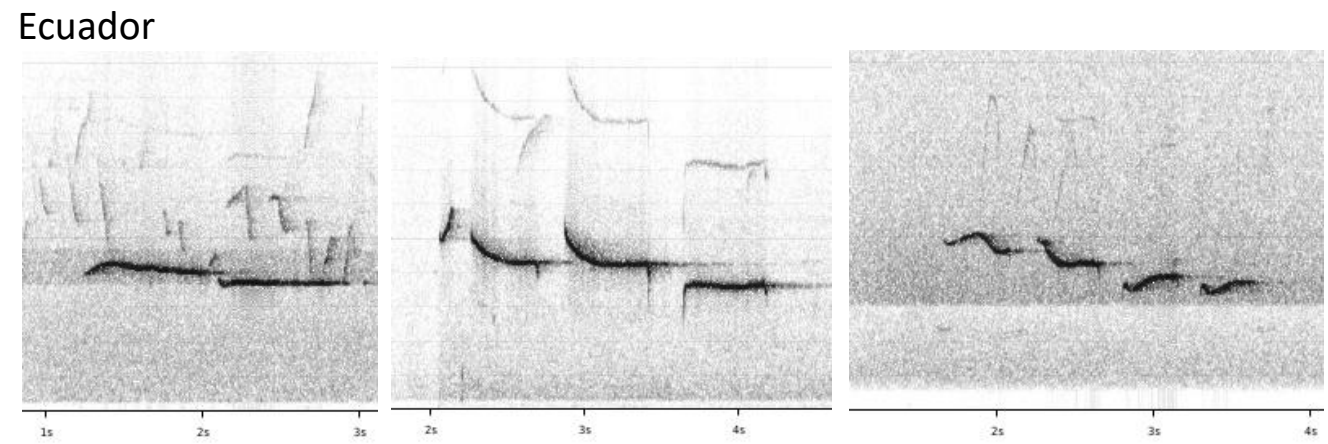

stictocephala (E slope of Andes in Peru)
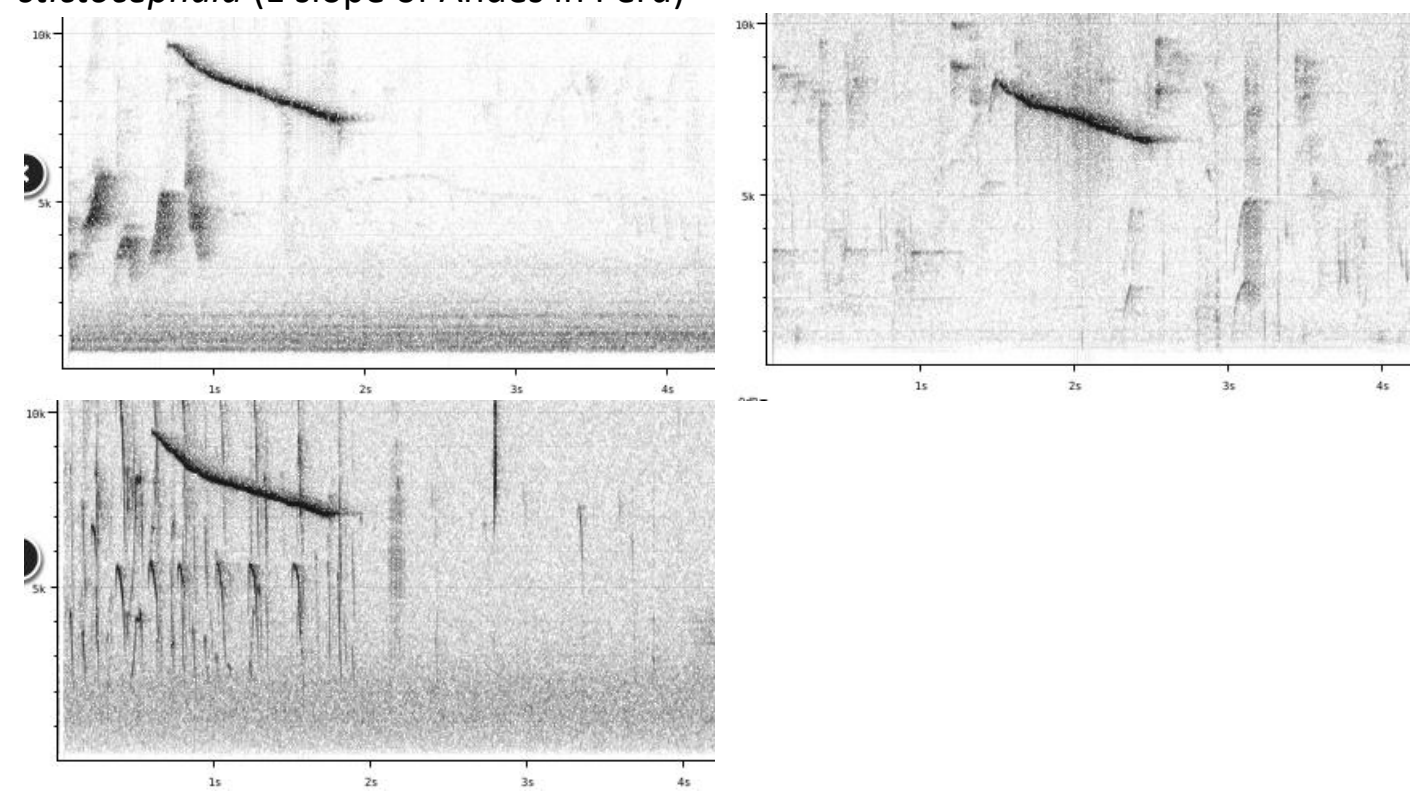

From the above examples, it is quite clear that all three races are vocally quite distinct:

Song of stictocephala is a single high-pitched downslurred whistle. Only carrikeri also reaches such high frequencies, but then always combines with lower-pitched whistle(s). A single recording from La Paz, Bolivia (ML193150) (where the species is not supposed to occur) sounds rather like northern races, but may well be a Russet-crowned Warbler Myiothlypis coronata:

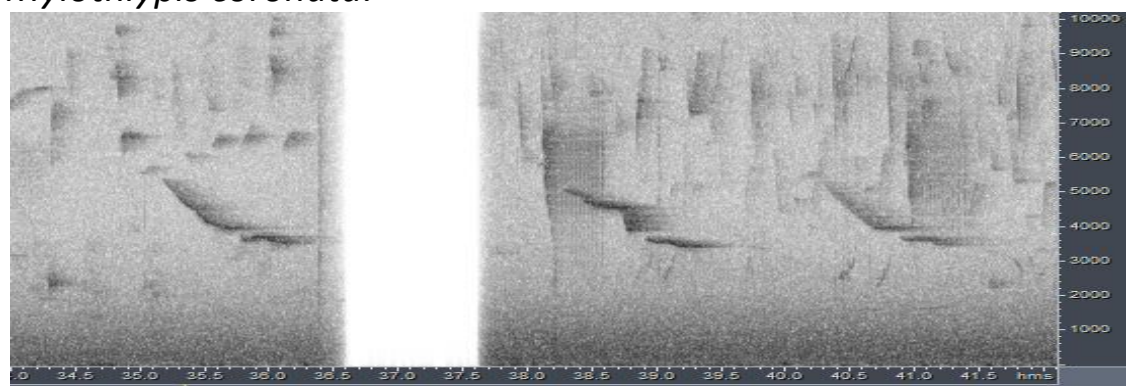

The marked vocal difference of race stictocephala has already been discussed in http://www.museum.Isu.edu/ Remsen/SACCprop392.htm . 

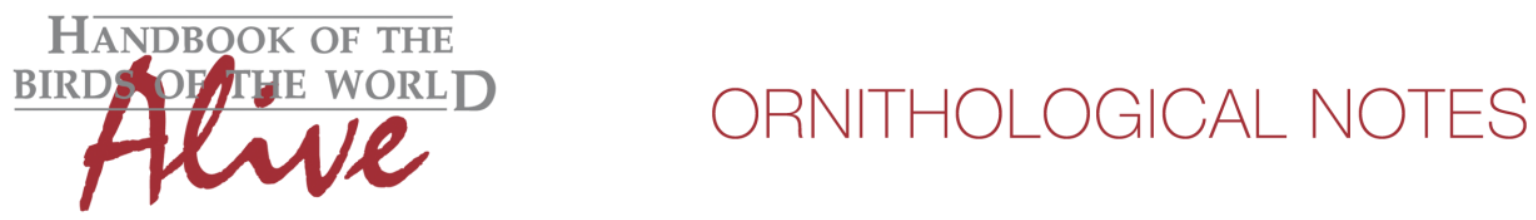

Song of the other two races consists of 2-4 whistles, in carrikeri the last whistle is markedly higher-pitched, while in taeniata the last whistle is actually the lowest-pitched.

We can quantify these vocal differences as follows:

stictocephala is unique in having a song consisting of a single whistle (vs typically 2-4 in other races)(score 3 ) and by singing at much higher frequencies (min. frequency $>6.5 \mathrm{kHz} v s$ typically down to $3-5 \mathrm{kHz}$ )(score 2 ). Application of Tobias criteria would lead to a total vocal score of about 5 .

carrikeri $(n=4)$ can further be distinguished from taeniata by reaching much higher frequencies (score 3).

This note was finalized on 5th July 2016, using sound recordings available on-line at that moment. We would like to thank the many sound recordists who placed their recordings for this species on XC and ML, in particular Nick Athanas, Peter Hosner, Dan Lane and Mark Robbins for recordings of stictocephala, and Nick Athanas, Diego Calderon, Oscar Laverde Jeremy Minns and Andrew Spencer for carrikeri.

\section{References}

Tobias, J.A., Seddon, N., Spottiswoode, C.N., Pilgrim, J.D., Fishpool, L.D.C. \& Collar, N.J. (2010). Quantitative criteria for species delimitation. Ibis 152(4): 724-746.

\section{Recommended citation}

Boesman, P. (2016). Notes on the vocalizations of Buff-breasted Mountain-tanager (Dubusia taeniata). HBW Alive Ornithological Note 403. In: Handbook of the Birds of the World Alive. Lynx Edicions, Barcelona. (retrieved from http://www.hbw.com/node/1253797 on 2 December 2016). 